\title{
Treatment Outcome of Adherent Placenta: An Experience at Tertiary Care Hospital
}

\author{
Rabia Wajid, ${ }^{1}$ Saira Bashir, ${ }^{2}$ Asif Hanif ${ }^{3}$
}

\section{Abstract}

Objective: The objective of this study was to see treatment outcome of morbidly adherent Placenta.

Methodology: This descriptive case series was carried out in Obstetrics and Gynae Unit-2 Lady Willingdon hospital Lahore from January 2013 to December 2014. In this period 127 females between 20 to 45 years with any parity were enrolled in this study. All the patients were diagnosed for Placenta Accreta, Increta and Percreta by color flow Doppler. Operative delivery was carried out in all. Cesarean Hysterectomy with or without Placental separation, conservative measures (uterine artery ligation, tamponade and hemostatic sutures) and Internal iliac ligation were used. The outcome measures recorded were total blood loss, neonatal birth weight, mean gestational age at delivery, neonatal Apgar score, intra and postoperative

\footnotetext{
${ }^{1}$ Senior Registrar, Dept of Obstetrics \& Gynaecology, Lady Willingdon Hospital, Lahore.

${ }^{2}$ Consultant Gynecologist, Dept of Obstetrics \& Gynaecology, Lady Willingdon Hospital, Lahore

${ }^{3}$ Assistant Prof. and HOD Biostatistics, Gulab Devi, PGMI, Lahore.
}

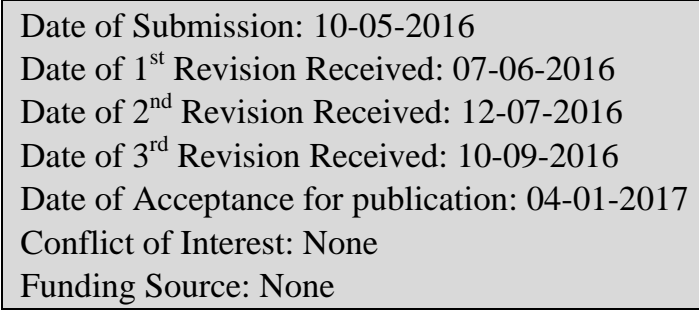

\section{Contribution}

All Authors have contributed in Study Design, Data Collection, Data Analysis, Data Interpretation, Manuscript Writing and Approval. complications and maternal mortality. Non-probability, sampling technique was used. The results were analyzed using SPSS version 20.

Results: The mean age of subjects in this study was $26.77 \pm 3.17$ years. Gestational age at diagnosis and at surgery was $34.83 \pm 1.94$ weeks and $36.19 \pm 1.557$ weeks respectively. According to previous history of cesarean section, $60(47.3 \%)$ had 1 previous C-section, 38 (29.9\%) had 2 previous C-section and rest of 29 (22.9\%) had $\geq 3 \mathrm{C}$-section. The diagnosis was made on Doppler Ultrasonography (USG) and the patients had surgery under emergency as well as elective conditions. We found that 96 (75.5\%) females had Accreta, $27(21.26 \%)$ had Increta and only $4(3.15 \%)$ females had Percreta. Placental separation was done in $63(49.6 \%)$ followed by Cesarean Hysterectomy were done in $36(57 \%)$, and conservative measures like tamponade, haemostatic sutures in Placental bed and Uterine artery ligation in the rest i.e. 27 (43\%). Non-separation of Placenta followed by direct Cesarean Hysterectomy was done in $64(50.3 \%)$, and Internal iliac ligation was done in 30 (23\%). During surgery the average blood loss was $2.97 \pm 1.36 \mathrm{~L}$. According to neonatal outcome Apgar score at 5 minutes was $5.69 \pm$ 1.446 and weight of new baby was $2.85 \pm 0.30 \mathrm{~kg}$. According to final outcome $83(65.35 \%)$ females were successfully discharged, 29 (22.83\%) had bladder rupture occurred in $29(22.83 \%)$ while maternal mortality occurred in 15 (11.81\%) only.

Conclusion: An increasing number of patients with morbidly adherent Placenta is coming up along with the rising incidence of C-Section. The key to the management of this condition is prompt diagnosis and referral to well-equipped hospitals having multi-disciplinary input. Conservative measures with uterine sparing are worth trying in selected cases.

Keywords: C-Section, adherent Placenta, Placenta 
Accreta, Placenta Increta, Placenta Percreta, Apgar score, blood transfusion, mortality.

\section{Introduction}

Morbidly Adherent Placenta (MAP) is a rare pregnancy complication in which placenta grows deeply into the wall of the uterus and is unable to detach. Abnormal Placental adherence can be divided into three categories: ${ }^{1}$ Placenta Accreta, in which Placental tissue penetrate the decidual surface of the myometrium; Placenta Increta, in which Placental villi reach more deeply within the myometrium, and Placenta Percreta where chorionic villi invade through the uterine serosa and may involve surrounding organs such as the bladder. The presence of Placenta Accreta/ Increta/Percreta is associated with many problems relating to pregnancy. ${ }^{1,2}$ The risk of Placenta Accreta/ Increta/Percreta seems to be raised in women who have a previous Cesarean section, other uterine surgery, an IVF pregnancy and Placenta Previa diagnosed during antenatal period. There was also an increased risk of Placenta Accreta/Increta/Percreta observed with increasing maternal age in women without a previous cesarean delivery. ${ }^{3}$

The diagnosis of Placenta Accreta starts with clinical suspicion in patients at risk. Ultrasound and Doppler are considered to be first line diagnostic methods because of their easy availability and are highly sensitive. ${ }^{4}$ Most dependable sign of Placenta Accreta on Doppler is the presence of irregular vascular spaces with arterial flow. ${ }^{5}$

Although management of Accreta, Percreta and Increta depends on extent of the problem, literature favors use of conservative treatment ${ }^{6}$ as it can help to avoid Cesarean Hysterectomy and involves a decreased rate of severe maternal morbidity in well-resourced centers. ${ }^{7}$ Where conservative management has high success rate, maternal morbidity and mortality are difficult to avoid in serious patients. The recent movement towards preservation of fertility includes adoption of measures include leaving the placenta after delivery with systemic uterine de vascularization, uterine artery embolization, uterine compression sutures and or over sewing of the placental vascular beds. Inappropriate management can comprise the maternal outcome resulting in many complications such as sepsis, septic shock, peritonitis, uterine necrosis, fistula, injury to adjacent organs, acute pulmonary edema, acute renal failure, deep vein thrombophlebitis or pulmonary embolism, or death due to postpartum hemorrhage or myelosuppression and nephrotoxicity related to intraumbilical methotrexate administration. ${ }^{7}$

However, limited data exist to plan the management of this condition. The existing literature consists predominately of case reports, and studies done using retrospective study of medical records, over a number of years in a single or small number of tertiary-care hospitals. ${ }^{8}$ In health system of Pakistan, the evaluation of post-cesarean morbidities has always been neglected. We designed this study to review management and outcome of Accreta, Percreta and Increta during and after surgery so that the most practical management suitable to our circumstances can be adopted.

\section{MATERIALS AND METHODS:}

This was descriptive case series and conducted at Department of Obstetrics and Gynecology, Lady Willingdon hospital Lahore.

The estimated sample size was 127 females using published statistics of maternal deaths as $30 \%$ at $8 \%$ margin of error and $95 \%$ confidence level. ${ }^{9}$ The following formula was used to estimate the sample size:

$$
n=\frac{z_{1-\frac{\alpha}{2}}^{2} p(1-p)}{d^{2}}
$$

Non-probability, consecutive sampling was used.

Multigravida patients with age 20-45 years with gestational age $>20$ weeks on early dating scan or last menstrual period, Patients with previous history of Csection, Women with low lying Placenta on Obstetrical scan were included.

The women with severe anemia $(\mathrm{Hb} \leq 7 \mathrm{~g} / \mathrm{dl})$ and severe blood loss at admission, having any ovarian or uterine pathology on ultrasound, Women with bleeding disorders or gynecological malignancy were excluded.

The 127 females meeting inclusion criteria were taken in this study. All targeted subjects were enrolled from Department of Obstetrics and Gynecology, Lady Willingdon Hospital, Lahore. Informed consent was obtained from females enrolled in study or from their attendants. Demographic details (like name, age, gestational age, parity, contact address) were recorded on a Performa. Patients were assessed for Accreta, Percreta and Increta with the help of Doppler USG. All patients were managed surgically.

A multidisciplinary approach with the involvement of senior obstetrician, anesthetist, pediatrician and hematologist was adopted. The protocol was to operate such cases electively at $36 / 37$ weeks or earlier 
in emergency if indicated. Steroids cover was given. Surgery was started early morning with eight units of blood and six units of fresh frozen plasma (FFP) in hand. Pfannensteil incision was given on skin. Transverse uterine incision was given away from Placental site. Neonate was handed over to pediatrician. Cesarean Hysterectomy was started in most of the cases of Placenta Increta and Percerta. Localized cases of Placenta Accreta were managed by conservative measures such as uterine artery ligation, tamponade (packing by ribbon gauze or balloon) and haemostatic sutures on the Placental bed. Failure of these measures led to Cesarean Hysterectomy. Internal artery ligation and bladder repair were performed as and when required.

Total blood loss was estimated and replaced. The patients were subjected to strict monitoring postoperatively. The patients were discharged after the removal of stitches.

\section{The Outcomes were Recorded as Follows}

Blood loss was defined in terms of intra and postoperative vaginal loss, blood in drains and massive Obstetric hemorrhage. APGAR score is the measure of the physical condition of a new born infant. It is obtained by adding 2,1 , or 0 for heart rate, respiratory rate, muscle tone, response to stimulation and skin coloration. Most babies born at term weigh between 2.5 to $4 \mathrm{~kg}$.

\section{Final Maternal Outcome}

- Successful discharge was defined as patient discharged when she was mobilized, tolerating food, passing urine and stool.

- Bladder rupture was defined as traumatic injury of bladder and urethra that involves damage by an outside force.
- Maternal mortality: Death of women while being pregnant or within 42 days of termination of pregnancy irrespective of duration and site of pregnancy from any cause related to or aggravated by pregnancy or its management and not from accidental or incidental causes.

The data were collected by principle investigator and analyzed with SPSS version 20. For qualitative data, i.e. parity, previous obstetrical history and diagnosis were presented as frequencies and percentages. Pie chart was also used for maternal outcome. For quantitative data, i.e. age, gestational age, blood loos during surgery Apgar score and weight of baby in $(\mathrm{Kg}$.) was presented as mean \pm S.D.

\section{Results}

The mean age of subjects in this study was $26.77 \pm$ 3.17 years. Gestational age at diagnosis and at surgery was $34.83 \pm 1.94$ weeks and $36.19 \pm 1.557$ weeks respectively. A total of $25(19.7 \%)$ had 1 parity, 39 $(50.4 \%)$ females had $2^{\text {nd }}$ parity and $63(49.6 \%)$ females had $\geq 3$ parity. According to previous history of cesarean section, $60(47.3 \%)$ had 1 previous C-section, 38 (29.9\%) had 2 previous C-section and rests of 29 (22.9\%) had $\geq 3$ C-section. A total of $99(78 \%)$ had no history of abortion, 21 (16.5\%) had 1 abortion and 7 $(5.5 \%)$ had 2 abortions in their previous pregnancies. The diagnosis was made on Doppler USG and we found that 96 (75.5\%) females had Accreta, 27 (21.26\%) had Increta and only $4(3.15 \%)$ females had Percreta. Placental separation was done in $63(49.6 \%)$ followed by Cesarean Hysterectomy done in $36(57 \%)$, and conservative measures like tamponade, haemostatic sutures in Placental bed in the rest of $27(43 \%)$. The conservative measures failed in three out of these twenty seven (11\%). Non separation of Placenta follo-

Table 1: Descriptive Statistics of Different Quantitative Variables.

\begin{tabular}{|l|l|c|c|}
\hline \multirow{2}{*}{ Demography } & & Mean & S.D \\
\hline \multirow{3}{*}{ Gestational age } & Age (years) & 26.77 & 3.17 \\
\cline { 2 - 4 } & Duration of pregnancy at diagnosis & 34.83 & 1.94 \\
\hline \multirow{3}{*}{$\begin{array}{l}\text { Feto-maternal } \\
\text { Outcome }\end{array}$} & Gestation age at C-section & 36.19 & 1.557 \\
\cline { 2 - 4 } & Blood loss during surgery (litres) & 2.97 & 1.36 \\
\cline { 2 - 4 } & Apgar score at 5 minutes of surgery & 5.69 & 1.446 \\
\cline { 2 - 4 } & Weight of baby at delivery (kg.) & 2.85 & 0.30 \\
\hline
\end{tabular}


Table 2: Parity, Previous Pregnancy Outcome and Diagnosis.

\begin{tabular}{|c|c|c|c|c|}
\hline & & & No. of Patients & Percentage \\
\hline \multirow{9}{*}{$\begin{array}{l}\text { Obstetrical } \\
\text { history }\end{array}$} & \multirow{3}{*}{ Parity } & 1 & 25 & 19.7 \\
\hline & & 2 & 39 & 30.7 \\
\hline & & $\geq 3$ & 63 & 49.6 \\
\hline & \multirow{3}{*}{$\begin{array}{l}\text { Previous } \\
\text { section }\end{array}$} & 1 & 60 & 47.2 \\
\hline & & 2 & 38 & 29.9 \\
\hline & & $\geq 3$ & 29 & 22.9 \\
\hline & \multirow{3}{*}{ Abortion } & 0 & 99 & 78 \\
\hline & & 1 & 21 & 16.5 \\
\hline & & 2 & 7 & 5.5 \\
\hline \multirow{3}{*}{\multicolumn{2}{|c|}{ Diagnosis }} & Accreta & 96 & 75.59 \\
\hline & & Increta & 27 & 21.26 \\
\hline & & Percreta & 4 & 3.15 \\
\hline \multirow{10}{*}{\multicolumn{2}{|c|}{ Surgical outcome }} & Separation & 63 & 49.6 \\
\hline & & Uterine Artery Ligation & 77 & 60.6 \\
\hline & & Tamponade & 52 & 40.9 \\
\hline & & Internal Iliac ligation & 30 & 23.62 \\
\hline & & Cesarean Hysterectomy & 82 & 64.56 \\
\hline & & Separation + Cesarean Hysterectomy & 36 & 28.34 \\
\hline & & Non Separation + Cesarean Hysterectomy & 64 & 50.2 \\
\hline & & Separation + Uterine Artery ligation+ Tamponade & 30 & 23.62 \\
\hline & & $\begin{array}{l}\text { Separation + Uterine Artery ligation+haemostatic } \\
\text { sutures }\end{array}$ & 11 & 8.66 \\
\hline & & Separation +Uterine Artery ligation + Tamponade & 22 & 17.32 \\
\hline
\end{tabular}

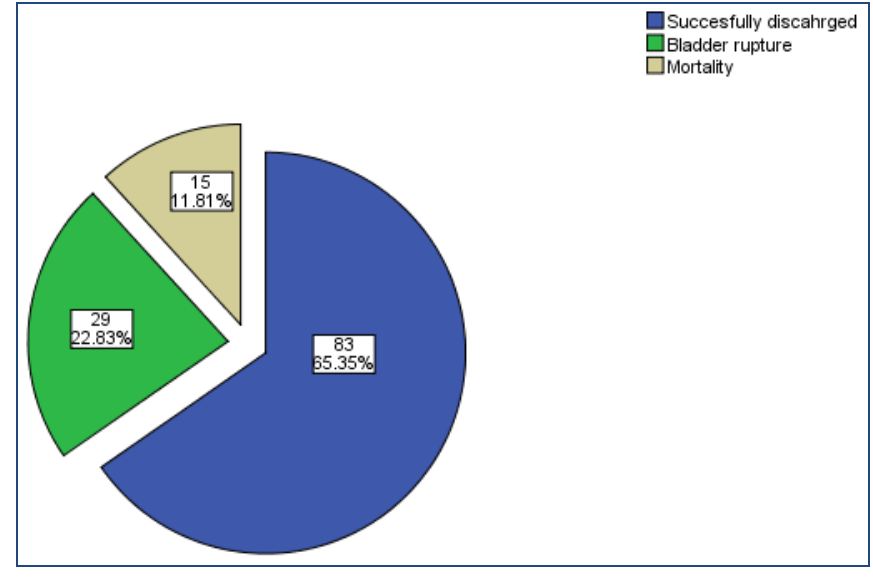

Fig. 1: Final Maternal Outcome. wed by direct Cesarean Hysterectomy was done in 64 $(50.3 \%)$, and Internal iliac artery ligation was done in $30(23 \%)$ after Cesarean Hysterectomy due to uncontrollable haemorrhage.

During surgery the average blood loss was $2.97 \pm$ $1.36 \mathrm{~L}$. According to neonatal outcome Apgar score at 5 minutes was $5.69 \pm 1.446$ and weight of new baby was $2.85 \pm 0.30 \mathrm{~kg}$. According to final outcome 83 $(65.35 \%)$ females were successfully discharged. Bladder rupture occurred in $29(22.83 \%)$ while maternal mortality occurred in $15(11.81 \%)$ mainly due to obstetric haemorrhage. In our study 3 patients who had trial haemostasis required total Cesarean Hysterectomy due to post-partum hemorrhage. One case in subtotal 
Cesarean Hysterectomy for Placenta Percreta with bladder invasion had re-laparotomy for bladder fistula, while two for severe postpartum hemorrhage. Two needed ventilator support.

\section{Discussion}

Three different types of abnormally invasive placentation are seen: Placenta Accreta, in which Placental villi invade the myometrial surface; Placenta Increta, in which Placental villi extend through the myometrium; and Placenta Percreta, where the villi penetrate through the myometrium to the uterine serosa and may invade surrounding organs, such as the bladder. ${ }^{8,10}$

In current study the mean age of subjects in this study was $26.77 \pm 3.17$ years. Gestational age at diagnosis and at surgery was $34.83 \pm 1.94$ weeks and $36.19 \pm 1.557$ weeks respectively. Similar age distribution is reported by Aggarwal et al i.e. the mean age and parity of the women was $27.7 \pm 4.2$ years. ${ }^{9}$ One more study reported similar mean age i.e. $27.2 \pm 3.8$ years. ${ }^{11}$ One study reported higher mean age $30.16 \pm$ 3.33 years as compared to our and above cited studies. A study reported $95 \%$ of cases found to have parity $1-5 .{ }^{12}$ We also found that A total of $25(19.7 \%)$ had 1 parity, $39(50.4 \%)$ females had $2^{\text {nd }}$ parity and 63 $(49.6 \%)$ females had $\geq 3$ parity.

Prenatal diagnosis using Doppler Ultrasound is important to reduce both fetomaternal morbidity and mortality. ${ }^{13,14}$ A study reported that $70 \%$ women had Placental localization which was almost similar to our diagnosis as we found that $96(75.5 \%)$ females had Accreta, 27 (21.26\%) had Increta and only 4 (3.15\%) females had Percreta. ${ }^{9}$ These figures are also confirmed in another study that reported $(64.7 \%)$ had scarred uteri with Placenta Previa. ${ }^{11}$ On the other hand these statistics in contradict a study which reported $19 \%^{12}$ and a local study which reported Placenta Previa as $21.5 \%{ }^{15} \mathrm{We}$ found that $60(47.3 \%)$ of the patients in this study had 1 previous C-section, 38 (29.9\%) had 2 previous C-section and rests of 29(22.9\%) had $\geq 3 \mathrm{C}$ section. Another study reported that $82.35 \%$ patients had previous Cesarean section. ${ }^{11}$

Placenta Accreta, Increta, or Percreta are associated with major pregnancy complications, including life-threatening maternal haemorrhage, large-volume blood transfusion, and peripartum Cesarean Hysterectomy. In a study conducted by Anjum Ara and colleagues $(87 \%)$ shad subtotal Cesarean Hysterectomy and (13\%) had total Cesarean Hysterectomy. ${ }^{16}$ This rate of Cesarean Hysterectomy was higher than that of our study and they did not use conservative measures or internal artery ligation. In another local study Cesarean Hysterectomy was performed in $50 \%$., trial haemostasis was performed in $7(21 \%)$. Subtotal Cesarean Hysterectomy was done in $9(28 \%){ }^{20}$ Internal iliac artery ligation was seen in $53.1 \%{ }^{19}$ while in current study its frequency was $23 \%$. In our study 3 patients who had trial haemostasis required total Cesarean Hysterectomy due to post-partum hemorrhage, whereas in the above mentioned study in the trial haemostasis cases, two cases underwent total Cesarean Hysterectomy due to massive postpartum hemorrhage same day. One case in subtotal Cesarean Hysterectomy for Placenta Percreta with bladder invasion had re-laparotomy for bladder fistula, while two for severe postpartum hemorrhage. Two needed ventilator support. ${ }^{16}$ In our study higher number 25 (19\%) required ventilator support. This was perhaps due to lack of availability of blood and blood products. These results match closely to ours. A Study by Aggarwal Rocha et al, out of 20 patients (90\%) had total Cesarean Hysterectomy, Internal iliac ligation in 5\% due to uncontrollable hemorrhage and $(5 \%)$ were administered methotrexate. ${ }^{9}$ our study showed an increased trend of using conservative measures as compared to other studies. Yap et al and other recent studies advocate that Placental separation should be kept to a minimum. ${ }^{16-19}$ In our study almost half of the patients did not undergo Placental separation.

According to neonatal outcome Apgar score at 5 minutes was $5.69 \pm 1.446$ and weight of new baby was $2.85 \pm 0.30 \mathrm{~kg}$. According to final outcome 83 $(65.35 \%)$ females were successfully discharged, 29 $(22.83 \%)$ had bladder rupture occurred in $29(22.83 \%)$ while maternal mortality occurred in 15 (11.81\%) only.

A study reported bladder injury during dissection occurred in 5 patients $(29.4 \%) .{ }^{11}$ That is slightly higher to our findings. Massive blood loss was a prominent feature of this condition, with a mean blood loss of 2.8 L. $^{11}$ We also found mean blood loss was $2.97 \pm$ $1.36 \mathrm{~L}$ that is almost similar to above study. High mortality rate is reported in literature i.e. were six (30\%) maternal deaths. $55 \%$ of the newborns were preterm and the perinatal mortality was $33.3 \%{ }^{9}$ Hassan et al reported mean Apgar scores at one and 5 minutes were 5.2 and 6.8 respectively. ${ }^{12}$ That is lower to our series. They reported $84 \%$ babies born alive out of which $79 \%$ were preterm and $21 \%$ were termed. ${ }^{12}$ While another study reported neonates with Placenta Previa mostly had low birth weight $<2.5 \mathrm{~kg}(45.5 \%$, 
$\mathrm{n}=15)$. Newborns delivered after Placenta Previa graded low Apgar score $<7$ at 5 minutes after birth $(51.5 \%, \mathrm{n}=17) .{ }^{15} \mathrm{We}$ found rate of preterm birth was $50.39 \%$ and low birth weight was seen in only $13.38 \%$ that lower to above cited study. ${ }^{12,15}$

As cesarean delivery rates rise, so will Placenta Previa rates. Abnormally implanted situations should be suspected and referred to well-equipped, well-staffed institutions prepared to deal with the eventualities. Every clinician doing cesarean deliveries must foresee the increased risks possible in the next pregnancy and be adequately trained to deal with all possible consequences.

The limitation of this study is a trend towards using less of conservative measures as compared to hysterectomy. This is due to a large number of cases landing in our hospital with no arrangements of blood and blood products, there by compelling towards aggressive management. More studies are required to establish the efficacy of conservative measures.

\section{Conclusion}

In the present times the gynecologists are facing the challenge of managing cases of morbidly adherent Placenta. These cases should best be dealt in tertiary care hospitals.

One of the most important things in dealing these cases is to anticipate the severity of the situation. The involvement of senior Obstetrician, Anesthetist and Hematologist is pivotal. Management should be tailored according to the severity of the situation. In cases of Placenta, Increta and Percreta early recourse to Cesarean Hysterectomy with or without Internal iliac ligation is a prudent approach. In less serious conditions conservative measures are worth trying.

\section{References}

1. Khong T. The pathology of Placenta Accreta, a worldwide epidemic. J Clinc Pathol. 2008; 61 (12): 1243-6.

2. Oyelese Y, Smulian JC, Placenta previa, Placenta Accreta, and vasa previa. Obs \& Gynecol. 2006; 107 (4): 927-41.

3. Fitzpatrick KE, Sellers S, Spark P, Kurinczuk JJ, Brocklehurst P, Knight M. Incidence and risk factors for Placenta Accreta/Increta/Percreta in the UK: a national case-control study. PLoS One. 2012; 7 (12): 52893.

4. Palacios J. Diagnosis and management of Placenta Accreta. Best Prac Res Clin Obstet Gynecol. 2008; 22:
1133-48.

5. $\mathrm{CH}$ C. The antenatal diagnosis of Placental attachment disorders. Curr Opin Obstet Gynecol. 2011; 23: 117-22.

6. Kayem G, Davy C, Goffinet F, Thomas C, Clement D, Cabrol D. Conservative versus extirpative management in cases of Placenta Accreta. Obstetrics \& Gynecology. 2004; 104 (3): 531-6.

7. Sentilhes L, Ambroselli C, Kayem G, Provansal M, Fernandez H, Perrotin F. et al,. Maternal outcome after conservative treatment of Placenta Accreta. Obstetrics \& Gynecology. 2010; 115 (3): 526-34.

8. Fitzpatrick K, Sellers S, Spark P, Kurinczuk J, Brocklehurst P, Knight M. The Management and Outcomes of Placenta Accreta, Increta, and Percreta in the United Kingdom: A Population-based Descriptive Study. Obs Anes Digest. 2015; 35 (1): 24-5.

9. Aggarwal R, Suneja A, Vaid NB, Yadav P, Sharma A, Mishra K. Morbidly Adherent Placenta: A Critical Review. J Obs \& Gyne Ind. 2012; 62 (1): 57-61.

10. Fitzpatrick K, Sellers S, Spark P, Kurinczuk J, Brocklehurst P, Knight M. The management and outcomes of Placenta Accreta, Increta, and Percreta in the UK: a population-based descriptive study. BJOG. 2014; 121 (1): 62-71.

11. Malhotra V, Bhuria V, Nanda S, Chauhan M, Rani A. Placenta Accreta: Five-Year Experience at a TertiaryCare Center. J Gynecol and Surg. 2014; 30 (2): 91-5.

12. Hasan S, Imtiaz F, Ali A, Sultana A. Feto-Maternal Outcome of Placenta Praevia after Previous Cesarean Section in a Tertiary Care Hospital. Epidemiology: Open Access. 2014; 2014.

13. Ansar A, Rauf N, Bano K, Liaquat N. Spontaneous rupture of primigravida uterus due to morbidly adherent Placenta. J Coll Physicians Surg Pak. 2009; 19 (732-3).

14. Choudry A, Choudry H, Shukr I, Bano I, Ahmasd S. Impact of antenatal diagnosis and management strategies in morbidly adherent Placenta. Pak J Med Res. 201; 50: 5-9.

15. Ayesha S, Fareed Z, Samina A, Nighat AA, Nafeesa A, Ayesha R, et al. Frequency of Placenta Previa with Previous C-Section. Pak J Med \& Health Sci. 2009; 3 (3): 233-7.

16. Hassan Anjum A, Hassan JA, Khan A. The management and maternal outcome in Morbidly adherent Placenta. Journal of Surgery. 2009; 14 (4): 166-169.17.

17. Mohyuddin S, Jabbar T. Management and maternal outcome in morbidly adherent Placenta. J Ayub Med Coll Abbottabad. 2011; 23 (2): 93-6.

18. Jaleel S, Nausheeen S, Akhtar ZA. Reducing morbidty and mortality in morbidly adherent Placenta: an experience. Pak J Surg. 2011; 27 (1): 59-63.

19. Yap YY, Pervin LC, Pain SR. Manual removal of suspected Placenta acreta at Ceaserean Cesarean Hysterectomy. Int J Gynaecol Obstet. 2008; 100: 186-7. 